\title{
Predictive Voltage Control Operating at Fixed Switching Frequency of a Neutral-Point Clamped Converter
}

\author{
Felipe Herrera \\ Roberto Cárdenas \\ Marco Rivera \\ José A. Riveros \\ Department of Electrical Engineering Department of Electrical Engineering Facultad de Ingeniería Facultad de Ingeniería \\ Universidad de Chile \\ Santiago, Chile \\ Universidad de Chile \\ Santiago, Chile \\ fherreraibanez@gmail.com \\ rcardenas@ing.uchile.cl \\ Universidad de Talca \\ Universidad de Talca \\ Curicó, Chile \\ Curicó, Chile \\ marcoriv@utalca.cl \\ jriverosv@utalca.cl
}

\author{
Patrick Wheeler \\ PEMC Research Group \\ The University of Nottingham \\ Nottingham, UK, and Ningbo, China \\ Pat.Wheeler@nottingham.ac.uk
}

\begin{abstract}
Uninterruptible power supply units are system formed by power electronics converters to supply sinusoidal voltages to feed critical loads. In this paper, a fixed switching frequency model predictive control strategy is presented for the control of the output voltage in an $L C$ filter connected to a threelevel NPC converter. The control objectives of the system are the tracking of the voltage reference and balance of the voltages of the dc-link capacitors. The mathematical model of the converter and the $L C$ filter is developed and the control strategy is explained. Simulation results obtained in the Matlab/Simulink enviroment are presented to validate the control strategy
\end{abstract}

Index Terms-Predictive control, DC-AC power converters, voltage control.

\section{INTRODUCTION}

When regulated sinusoidal voltages are required by a load, the solution is to use inverters with an $L C$ output filter to generate ac output voltages with very low harmonic content [1]. One application of this is as the main inverter of an uninterruptible power supply (UPS) system. UPS units are composed of power electronics converters designed to feed critical linear and nonlinear loads such as medical and industrial equipment [2].

For the operation of the inverter the most common approach is to use linear control because of its well-known design and simple implementation. These linear control strategies are PI-based linear cascaded control loops with coordinate transformation (such as the Clarke transform and the Park transform) and modulation techniques such as carrier-based PWM and space vector modulation [3]. The modulation technique is used to linearize the converter and generate the commutation signals based on a time-average principle. Advantages of linear control strategies are the fixed switching frequency and easiness to extend the method to different converter topologies by changing the modulation technique used, etc. but it has some disadvantages such as the difficulty to include contraints and nonlinearities and the necessity of a modulator resulting in slower dynamics. The development of semiconductor technology has increased the processing capability of digital microprocessors and reduced their price allowing the exploration and implementation of new and more complex control schemes. These techniques such as fuzzy control, robust control, sliding mode control and model preditive control (MPC) are more advanced than standard PID control and thus are denominated as advanced control [4]. Predictive control refers to a wide class of controllers such as deadbeat control, hysteresis-based, trayectory-based and MPC [5]. These control techniques shares the same common characteristic which is the use of the mathematical model of the system to predict the future behaviour of the controlled variables over a prediction horizon $N$ to select the appropiate control action based on an optimization criterion [6]. Advantages of predictive control are: applicability to a variety of systems, nonlinearities can be included in the model avoiding the need of linearizing for a given operating point, constraints can be included in the optimization criterion, the multivariable case can be easily included and the possibility to avoid the cascaded structure of linear control schemes resulting in fast transient response. The disadvantages of predictive control strategies are the high computational burden and the need of very good mathematical models of the system under control [4].

FCS-MPC is a predictive control strategy which use the discrete nature of the converter. In every sampling instant the controlled variables are measured and fed to the discrete-time model of the system to predict their future behavior for all possible switching states of the converter and compute a cost function. The cost function depends on the control objetives and can be the absolute error, quadratic error or time-average error between the reference and measured variables [7]. The switching state who minimizes the cost function is stored and 
applied in the next sampling instant. The strategy does not need a modulator resulting in a variable switching frequency. A FCS-MPC algorithm with constant switching frequency is preferred because it allows easy filter design in applications such as grid-connected converters and inverters with output $L C$ filter $[4,8]$. A solution to the switching frequency problem is a FCS-MPC algorithm called Modulated Model Predictive Control $\left(\mathrm{M}^{2} \mathrm{PC}\right)$. In $\mathrm{M}^{2} \mathrm{PC}$, a modulation scheme is included in the cost function minimization by selecting and applying, in every sampling instant, two or more switching states with their corresponding application times [9]. This approach has been applied to many power converter topologies including the NPC converter [8-14] .

In this paper, a $\mathrm{M}^{2} \mathrm{PC}$ strategy is proposed for the output voltage control and $d c$-link capacitor voltage balance of a NPC converter connected to a $L C$ filter feeding a linear resistive load. In Section II the mathematical model of the converter and load is developed, in section III the $\mathrm{M}^{2} \mathrm{PC}$ strategy is explained and in section IV the control strategy is validated with a Matlab/Simulink simulation.

\section{Topology and Mathematical Model of the CONVERTER}

In Fig. 1 a three-level neutral-point clamped (NPC) converter connected to a resistive load through a $L C$ filter is shown.

The NPC converter is a multilevel inverter which means that the converter transforms a fixed $d c$ voltage to a $a c$ voltage with variable magnitude and frequency. The $d c$-link is formed by two cascaded $d c$ capacitors who provide a floating neutral point $(O)$. The converter topology consist of three phases (or legs) connected in parallel with four high-power switching devices per phase. The high-power switching devices can be either IGBT or GCT [15]. Two series connected diodes (denominated as clamping diodes) are connected to the node

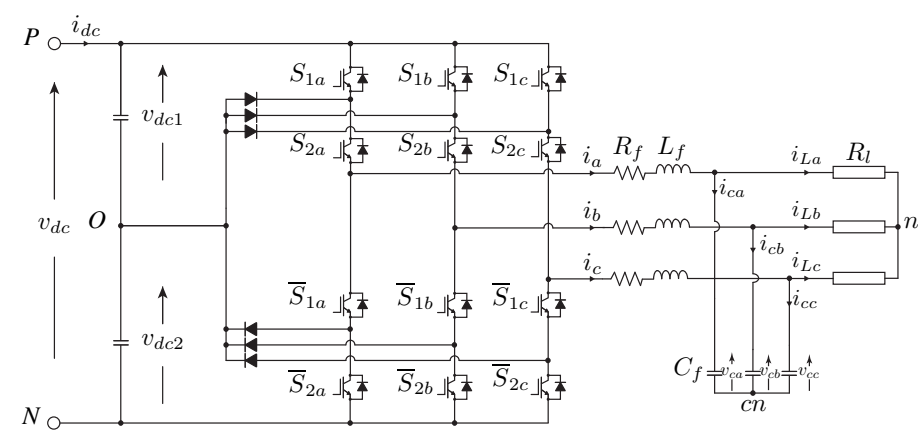

Fig. 1. NPC converter connected to a resistive load through an $L C$ filter.

Table I

SWITCHING STATES AND INVERTER TERMINAL VOLTAGE.

\begin{tabular}{c|cc|rc|c}
$S_{x}$ & $S_{1 x}$ & $S_{2 x}$ & $\overline{S_{1 x}}$ & $\overline{S_{2 x}}$ & $v_{x N}$ \\
\hline \hline $1(\mathrm{P})$ & 1 & 1 & 0 & 0 & $v_{d c 1}+v_{d c 2}$ \\
$0(\mathrm{O})$ & 0 & 1 & 1 & 0 & $v_{d c 2}$ \\
$-1(\mathrm{~N})$ & 0 & 0 & 1 & 1 & 0
\end{tabular}

between the upper switching devices (with switching signals $S_{1 x}$ and $S_{2 x}$, with $\left.\mathrm{x} \in\{a, b, c\}\right)$ and the node between the lower switching devices (with switching signals $\overline{S_{1 x}}$ and $\overline{S_{2 x}}$ ). Since the converter operation don't allow all the switching devices to be in the ON state at the same time, the lower switching devices work in a complementary manner with the upper switching devices. The node between the clamping diodes is connected to the floating neutral point of the $d c$-link. The switching state, $S_{x}$, summarise the switching devices state (ON or OFF) of the four switches in one of the three phases. Table I shows the relationship between the switching state, the switching signals of the switching devices in one phase and the inverter terminal voltage, $v_{x N}(t)$. The voltage $v_{x N}(t)$ can be expressed as a function of the switching signals of the upper switching devices and the voltages of the $d c$-link capacitors as follows:

$$
v_{x N}(t)=S_{1 x} v_{d c 1}(t)+S_{2 x} v_{d c 2}(t)
$$

The voltages of the $d c$-link capacitors can be expressed with the differential equations in (2), where $i_{d c 1}(t)$ and $i_{d c 2}(t)$ are the current through the upper capacitor and the current through the lower capacitor, respectively.

$$
\begin{aligned}
& \frac{d v_{d c 1}(t)}{d t}=\frac{1}{C_{1}} i_{d c 1}(t) \\
& \frac{d v_{d c 2}(t)}{d t}=\frac{1}{C_{2}} i_{d c 2}(t)
\end{aligned}
$$

The currents through the $d c$-link capacitors, $i_{d c 1}(t)$ and $i_{d c 2}(t)$, are a function of the output currents $i_{x}(t)$ and the switching states of the converter and can be determined by the equation presented in [16] as follows:

$$
\begin{aligned}
& i_{d c 1}(k)=i_{d c}(k)-H_{1 a} i_{a}(k)-H_{1 b} i_{b}(k)-H_{1 c} i_{c}(k) \\
& i_{d c 2}(k)=i_{d c}(k)+H_{2 a} i_{a}(k)+H_{2 b} i_{b}(k)+H_{2 c} i_{c}(k)
\end{aligned}
$$

$H_{1 x}$ and $H_{2 x}$ are piecewise-defined functions whose values dependes on the switching states of the converter. The function $H_{1 x}=1$ if and only if $S_{x}=1 ; H_{1 x}=0$ in any other case. The function $H_{2 x}=1$ if and only if $S_{x}=-1 ; H_{2 x}=0$ in any other case.

This converter has 3 switching states per phase, therefore there are $3^{3}=27$ possible combinations of the switching states. Considering a three-phase balanced load the $a c$ side analysis can be simplified using the Clarke transform. Applying the Clarke transform to the three-phase inverter terminal voltages, 19 different voltage space vectors are generated from the 27 combinations of the switching states. Those combinations who generate the same voltage vector are called redundant. The vectors are classified based on their length in zero vector $\left(\mathbf{v}_{\mathbf{0}}\right)$, small vectors $\left(\mathbf{v}_{1}-\mathbf{v}_{6}\right)$, medium vectors $\left(\mathbf{v}_{7^{-}}\right.$ $\left.\mathbf{v}_{12}\right)$ and large vectors $\left(\mathbf{v}_{13}-\mathbf{v}_{18}\right)$. The projection of the vectors in the $\alpha-\beta$ plane is shown in Fig. 2. The plane is divided in six triangular sectors and each sector is divided in four regions. The following current and voltage space vectors are defined for the $L C$ filter and load variables: 


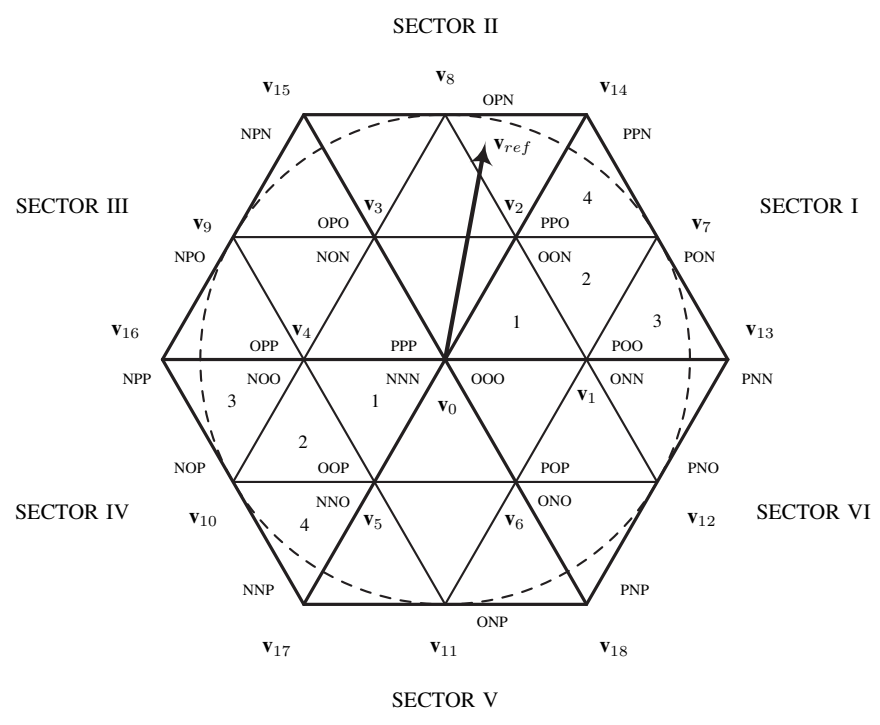

Fig. 2. Space vector diagram of the NPC converter.

$$
\begin{gathered}
\mathbf{v}(t)=(2 / 3)\left(v_{a N}(t)+\mathbf{a} v_{b N}(t)+\mathbf{a}^{2} v_{c N}(t)\right) \\
\mathbf{i}(t)=(2 / 3)\left(i_{a}(t)+\mathbf{a} i_{b}(t)+\mathbf{a}^{2} i_{c}(t)\right) \\
\mathbf{v}_{c}(t)=(2 / 3)\left(v_{c a}(t)+\mathbf{a} v_{c b}(t)+\mathbf{a}^{2} v_{c c}(t)\right) \\
\mathbf{i}_{L}(t)=(2 / 3)\left(i_{L a}(t)+\mathbf{a} i_{L b}(t)+\mathbf{a}^{2} i_{L c}(t)\right)
\end{gathered}
$$

where $\mathbf{a}=e^{j(2 \pi / 3)}, \mathbf{v}(t)$ is the space vector of the inverter terminal voltages, $\mathbf{i}(t)$ is the space vector of the inductors current in the $L C$ filter, $\mathbf{v}_{c}(t)$ is the space vector of the capacitors voltages in the $L C$ and $\mathbf{i}_{L}(t)$ is the space vector of the load currents. The differential equations who describe the dynamics of the $a c$ side are:

$$
\begin{gathered}
\frac{d \mathbf{v}_{c}}{d t}=\frac{1}{C_{f}} \mathbf{i}-\frac{1}{C_{f}} \mathbf{i}_{L} \\
\frac{d \mathbf{i}}{d t}=\frac{1}{L_{f}} \mathbf{v}-\frac{1}{L_{f}} \mathbf{v}_{c}-\frac{R_{f}}{L_{f}} \mathbf{i}
\end{gathered}
$$

where $C_{f}, L_{f}$ y $R_{f}$ are the filter capacitance, filter inductance and filter resistance, respectively. To implement the control algorithm in a digital platform the continuous-time equations need to be discretized. The discrete-time equations are obtained applying the Euler forward method.

$$
\frac{d \mathbf{x}(t)}{d t} \approx \frac{\mathbf{x}(k+1)-\mathbf{x}(k)}{T_{s}}
$$

Replacing (7) in (2), (5) and (6):

$$
\begin{gathered}
v_{d c z}=v_{d c z}(k)+\frac{T_{s}}{C_{z}} i_{d c z}(k), \quad z \in\{1,2\} \\
\mathbf{i}(k+1)=\left[1-\frac{R_{f} T_{s}}{L_{f}}\right] \mathbf{i}(k)+\frac{T_{s}}{L_{f}}\left[\mathbf{v}(k)-\mathbf{v}_{c}(k)\right] \\
\mathbf{v}_{c}(k+1)=\mathbf{v}_{c}(k)+\frac{T_{s}}{C_{f}}\left[\mathbf{i}(k+1)-\mathbf{i}_{L}(k)\right]
\end{gathered}
$$

\section{Fixed Switching Frequency Predictive VOLTAGE CONTROL}

$\mathrm{M}^{2} \mathrm{PC}$ is a combination of the operation principles of SVM and FCS-MPC. In every switching instant $T_{s}$ a switching sequence is applied to the converter, the switching sequence consist in the controlled application of the switching states of the voltage vectors that form the region where $\mathbf{v}_{r e f}$ is located. The transition between one switching state and the next should follow a criterion. The criteria are: (a) at every transition only one leg of the converter can change his switching state and (b) in one sampling interval only two switches per leg can switch states, one for turn-ON and then for turn-OFF. Following these criteria the NPC space vector diagram is analized finding 36 possible switching sequences. Consider region 1 in sector I which is formed by the vectors $\mathbf{v}_{0}, \mathbf{v}_{1}$ and $\mathbf{v}_{2}$. These are redundant vectors enabling the possibility to form two switching sequences with them: $\mathbf{v}_{0}(\mathrm{OOO})-\mathbf{v}_{1 P}(\mathrm{POO})-\mathbf{v}_{2 P}(\mathrm{PPO})-\mathbf{v}_{0}(\mathrm{PPP})$ and $\mathbf{v}_{0}(\mathrm{OOO})-\mathbf{v}_{2 N}(\mathrm{OON})-\mathbf{v}_{1 N}(\mathrm{ONN})-\mathbf{v}_{0}(\mathrm{NNN})$. The difference between both switching sequences is the use of the $d c$ link. The switching sequence of region 1 in sector $I$ is shown in Fig. 3 and the switching sequence of the optimal vectors is shown in Fig. 4, the vector $\mathbf{v}_{0}$ is the vector with most redundant states in the sequence. The control objetives are: (a) track of the reference voltage and (b) voltage balance in the $d c$-link capacitors. The following cost funcion is defined:

$$
g_{j}=\left(v_{c \alpha}^{*}-v_{c \alpha}^{p}\right)^{2}+\left(v_{c \beta}^{*}-v_{c \beta}^{p}\right)^{2}+\lambda_{d c}\left(v_{d c 1}^{p}-v_{d c 2}^{p}\right)^{2}
$$

where $\lambda_{d c}$ is a weighting factor and $j \in\{0,1,2\}$. The discrete equations of the load are used for the prediction of the state variables with a prediction horizon $N=1$. The sequence that minimize the global cost function $g$ is applied:

$$
g=d_{0} g_{0}+d_{1} g_{1}+d_{2} g_{2}
$$

The variables $d_{j}$ are the duty cycles of the voltage vectors and depends on the cost function of every vector in the sequence.

$$
\begin{gathered}
d_{0}=1-d_{1}-d_{2} \\
d_{1}=g_{1} g_{3} /\left(g_{1} g_{2}+g_{2} g_{3}+g_{1} g_{3}\right) \\
d_{2}=g_{1} g_{2} /\left(g_{1} g_{2}+g_{2} g_{3}+g_{1} g_{3}\right)
\end{gathered}
$$

The application time of every vector depends on the duty cycles and the sampling time.

$$
\begin{aligned}
& T_{0}=T_{s} d_{0} \\
& T_{1}=T_{s} d_{1} \\
& T_{2}=T_{s} d_{2}
\end{aligned}
$$

In Fig. 5 the block diagram of $\mathrm{M}^{2} \mathrm{PC}$ is shown.

\section{Simulation Results}

In this section the simulation results of the proposed control strategy are presented. In Table II the simulation parameters are shown. The results are presented for steady state and transient state with a step change of the reference voltage. 


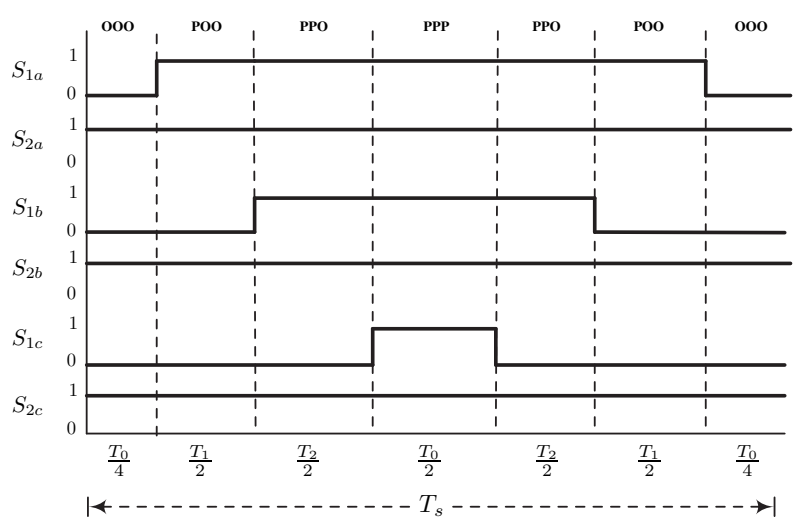

Fig. 3. Switching sequence formed by the vectors $\mathbf{v}_{0}(\mathrm{OOO})-\mathbf{v}_{1 P}(\mathrm{POO})-$ $\mathbf{v}_{2 P}(\mathrm{PPO})-\mathbf{v}_{0}(\mathrm{PPP})$

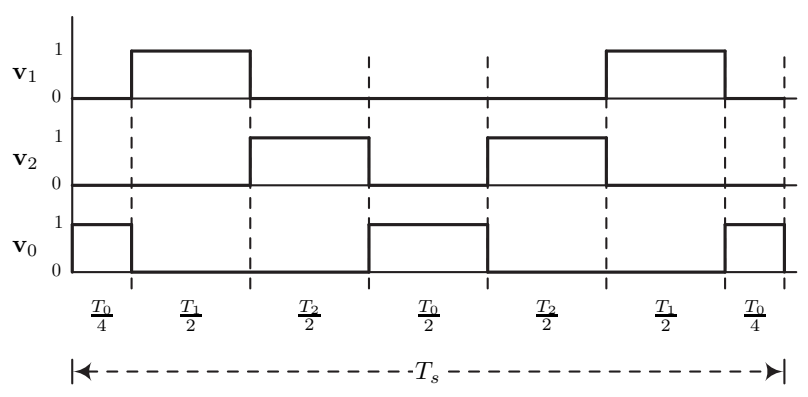

Fig. 4. Switching sequence for the optimal vectors.

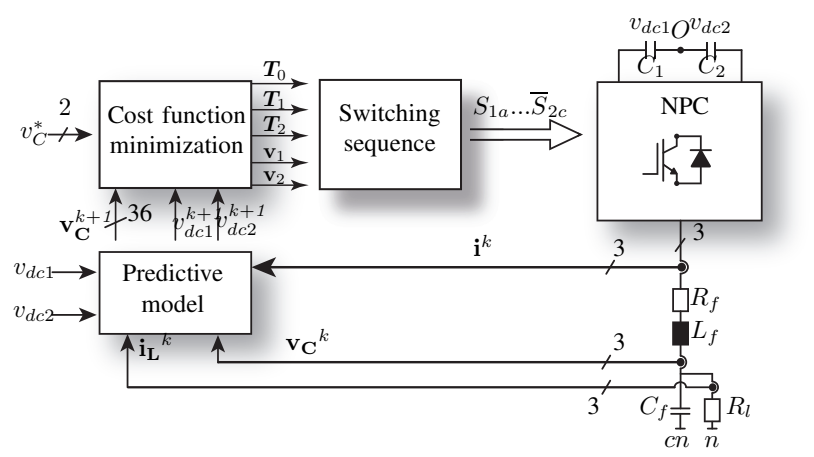

Fig. 5. Block diagram of $\mathrm{M}^{2} \mathrm{PC}$ applied to a NPC converter connected to a $L C$ filter.

\section{A. Results in steady state}

In Fig. 6 the reference voltage and the voltage in the capacitors of the $L C$ filter is shown in the upper graph and the current through the $L C$ filter inductors is shown in the lower graph. In steady state, the system is capable of following the reference voltage fulfilling the first control objetive.

In Fig. 7 the voltage in the capacitors of the $d c$-link is shown in the upper graph and the current to the load are shown in the lower graph. The voltages of the $d c$-link capacitors are kept at half the voltage applied to the $d c$-link each and the voltage error between $v_{d c 1}$ and $v_{d c 2}$ oscillates between \pm 0.1 [V]. The $\mathrm{M}^{2} \mathrm{PC}$ is capable of balance the $d c$-link capacitors in steady state.
Table II

SIMULATION PARAMETERS

\begin{tabular}{l|l|l} 
Variables & Description & Value \\
\hline \hline$V_{f}$ & $d c$-source voltage & $300[\mathrm{~V}]$ \\
$C_{d c}$ & $d c$-link capacitors & $4700[\mu \mathrm{F}]$ \\
$R_{f}$ & $L C$ filter resistance & $0.05[\Omega]$ \\
$L_{f}$ & $L C$ filter inductance & $10[\mathrm{mH}]$ \\
$C_{f}$ & $L C$ filter capacitance & $80[\mu \mathrm{F}]$ \\
$R_{L}$ & Load resistance & $10[\Omega]$ \\
$f_{r}$ & Reference signal frequency & $50[\mathrm{~Hz}]$ \\
$T_{s}$ & Sampling time & $50[\mu \mathrm{s}]$ \\
& Simulation step & $1[\mu \mathrm{s}]$ \\
$\lambda_{d c}$ & Weighting factor & 0.4 \\
\hline \hline
\end{tabular}
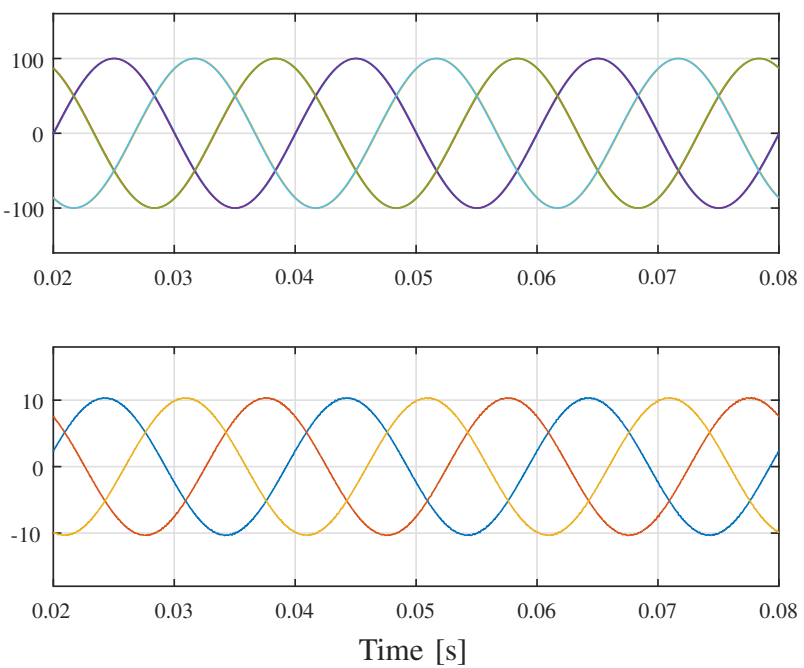

Fig. 6. Reference voltage $\mathbf{v}_{c}^{*}(t)$ and voltage in the $L C$ filter capacitors, $\mathbf{v}_{c}(t)$ [V] (upper). Currents in the inductors of the LC filter, $\mathbf{i}(t)$ [A] (lower.)
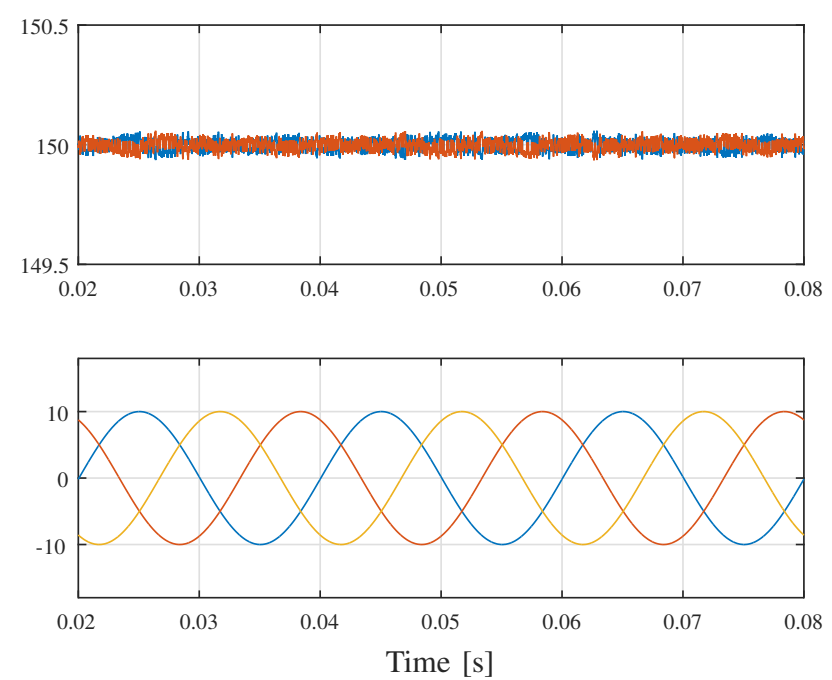

Fig. 7. $d c$-link capacitors voltages, $v_{d c 1}(t)[\mathrm{V}]$ and $v_{d c 2}(t)$ [V] (upper). Load currents $\mathbf{i}_{\mathbf{L}}(t)[\mathrm{A}]$ (lower).

In Fig. 8 the harmonic spectrum of the voltage and current 

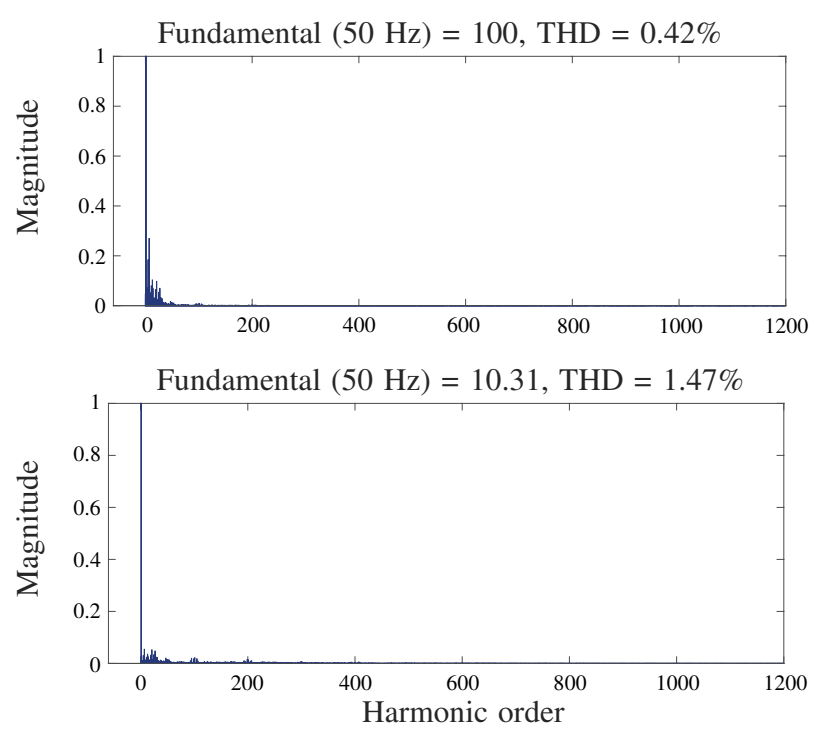

Fig. 8. Harmonic spectrum of the $L C$ filter capacitor in phase $a, v_{c a}(t)$ (upper). Harmonic spectrum of the current through the $L C$ filter inductor in phase a $i_{a}(t)$ (lower).

in the capacitors and inductors of the $L C$ filter is shown. The harmonic distorsion of the current and the voltages is very low with a THD of $0.42 \%$ for the voltage of the $L C$ filter capacitors and a THD of $1.47 \%$ for the current through the inductors of the filter. This values are obtained when the system is working with a device switching frequency of 10 $[\mathrm{kHz}]$. The device switching frequency is half the sampling frequency of 20 [kHz].

\section{B. Results in transient state}

In Fig. 9 the reference voltages and voltages in the capacitors of the $L C$ filter are shown in the upper graph for a step change in the reference from 100 [V] to 150 [V] and the currents in the $L C$ filter inductors is shown in the lower graph. For a step load in the voltage refence, the system is capable of tracking the reference with a fast transient response fulfilling the tracking objetive.

In Fig. 10 the voltage in the capacitors of the $d c$-link is shown in the upper graph and the currents to the load are shown in the lower graph for a step change in the voltage reference of $100[\mathrm{~V}]$ to 150 [V]. The voltage error between the capacitors increase from $\pm 0.1[\mathrm{~V}]$ to $\pm 0.4[\mathrm{~V}]$ at the step time. This is explained because the weigthing factor of the voltage balance objetive in the cost function is not adjusted to the new conditions of the system. Since the difference is small, the control strategy is capable of fulfill the voltage balance in the $d c$-link capacitors objetive.

\section{Conclusions}

In this paper, a fixed switching frequency model predictive control strategy was developed for the voltage control of an $L C$ filter connected to a three-level NPC converter. The mathematical model of the NPC converter and the $L C$ filter is developed and used for the prediction of the states variables
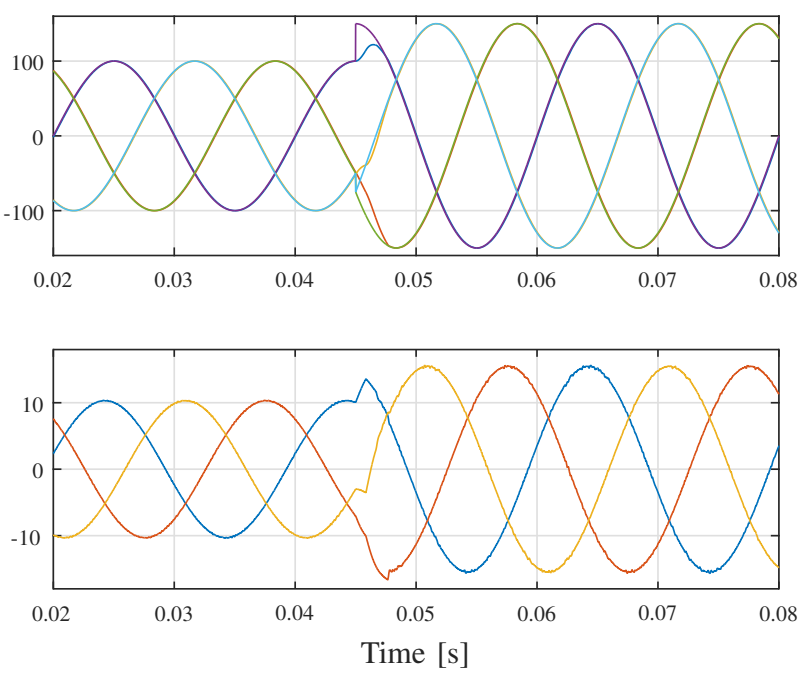

Fig. 9. Reference voltage $\mathbf{v}_{c}^{*}(t)$ and voltage in the $L C$ filter capacitors, $\mathbf{v}_{c}(t)$ [V] (upper). Currents in the inductors of the LC filter, $\mathbf{i}(t)[\mathrm{A}]$ (lower.)
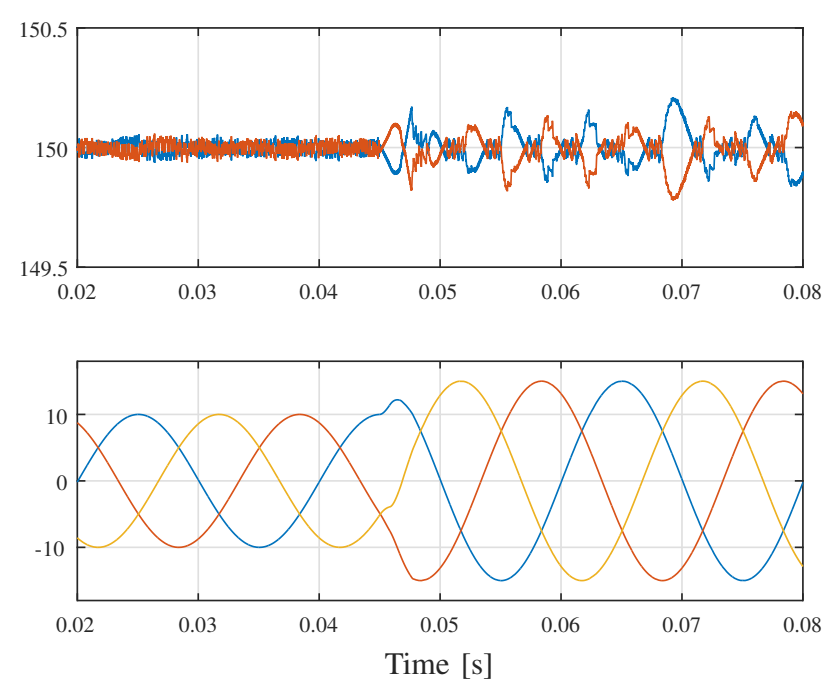

Fig. 10. $d c$-link capacitors voltages, $v_{d c 1}(t)[\mathrm{V}]$ and $v_{d c 2}(t)[\mathrm{V}]$ (upper). Load currents $\mathbf{i}_{\mathbf{L}}(t)[\mathrm{A}]$ (lower).

and the $\mathrm{M}^{2} \mathrm{PC}$ control strategy is explained. Simulation results of the control strategy were presented for steady state and transient state with a step change of the reference voltage from $100[\mathrm{~V}]$ to $150[\mathrm{~V}]$. The simulations results shows that the control strategy is capable of tracking the reference voltage and mantain balanced the voltage in the capacitors of the $d c$-link under both simulation conditions presented. The control strategy is based on the SVM operation principle and is restricted by the same operational limits of the modulation such as the maximum modulation index of $(\sqrt{(3) / 3}) v_{d c}$.

\section{ACKNOWLEDGMENT}

The authors are thankful for the funding to the program FONDECYT Regular through the project 1160690, Postdoctoral 3170014 and the Universidad de Talca through the fund for scientific research of undergraduate students. 


\section{REFERENCES}

[1] V. K. Singh, R. N. Tripathi, and T. Hanamoto, "Model-based design approach for implementation of finite state MPC," in 2018 13th IEEE Conference on Industrial Electronics and Applications (ICIEA), May 2018, pp. 881-886.

[2] R. E. Carballo, F. Bottern, G. G. Oggier, and G. O. Garca, "Multiple resonant controllers strategy to achieve fault ride-through and high performance output voltage in UPS applications," IET Power Electronics, vol. 11 , no. 15 , pp. 2415-2426, 2018.

[3] S. Kouro, M. A. Perez, J. Rodriguez, A. M. Llor, and H. A. Young, "Model Predictive Control: MPC's Role in the Evolution of Power Electronics," IEEE Industrial Electronics Magazine, vol. 9, no. 4, pp. 8-21, Dec. 2015.

[4] P. Cortes, M. P. Kazmierkowski, R. M. Kennel, D. E. Quevedo, and J. Rodriguez, "Predictive Control in Power Electronics and Drives," IEEE Transactions on Industrial Electronics, vol. 55, no. 12, pp. 43124324, Dec. 2008.

[5] J. Rodriguez and P. Cortes, "Model Predictive Control," in Predictive Control of Power Converters and Electrical Drives. Wiley-IEEE Press, 2012, pp. 248-. [Online]. Available: http://ieeexplore.ieee.org/xpl/articleDetails.jsp?arnumber $=6199000$

[6] S. Vazquez, J. I. Leon, L. G. Franquelo, J. Rodriguez, H. A. Young, A. Marquez, and P. Zanchetta, "Model Predictive Control: A Review of Its Applications in Power Electronics," IEEE Industrial Electronics Magazine, vol. 8, no. 1, pp. 16-31, Mar. 2014.

[7] S. Kouro, P. Cortes, R. Vargas, U. Ammann, and J. Rodriguez, "Model Predictive ControlA Simple and Powerful Method to Control Power Converters," IEEE Transactions on Industrial Electronics, vol. 56, no. 6, pp. 1826-1838, Jun. 2009.

[8] F. Donoso, A. Mora, R. Crdenas, A. Angulo, D. Sez, and M. Rivera, "Finite-Set Model-Predictive Control Strategies for a 31-NPC Inverter Operating With Fixed Switching Frequency," IEEE Transactions on Industrial Electronics, vol. 65, no. 5, pp. 3954-3965, May 2018.

[9] L. Tarisciotti, P. Zanchetta, A. Watson, J. C. Clare, M. Degano, and S. Bifaretti, "Modulated Model Predictive Control for a Three-Phase Active Rectifier," IEEE Transactions on Industry Applications, vol. 51, no. 2, pp. 1610-1620, Mar. 2015.

[10] L. Tarisciotti, A. Formentini, A. Gaeta, M. Degano, P. Zanchetta, R. Rabbeni, and M. Pucci, "Model Predictive Control for Shunt Active Filters With Fixed Switching Frequency," IEEE Transactions on Industry Applications, vol. 53, no. 1, pp. 296-304, Jan. 2017.

[11] M. Rivera, M. Perez, V. Yaramasu, B. Wu, L. Tarisciotti, P. Zanchetta, and P. Wheeler, "Modulated model predictive control (M2pc) with fixed switching frequency for an NPC converter," in 2015 IEEE 5th International Conference on Power Engineering, Energy and Electrical Drives (POWERENG), May 2015, pp. 623-628.

[12] M. Vijayagopal, P. Zanchetta, L. Empringham, L. D. Lillo, L. Tarisciotti, and P. Wheeler, "Modulated model predictive current control for direct matrix converter with fixed switching frequency," in 2015 17th European Conference on Power Electronics and Applications (EPE'15 ECCEEurope), Sep. 2015, pp. 1-10.

[13] L. Tarisciotti, J. Lei, A. Formentini, A. Trentin, P. Zanchetta, P. Wheeler and M. Rivera, "Modulated Predictive Control for Indirect Matrix Converter," IEEE Transactions on Industry Applications, vol. 53, no. 5, pp. 4644-4654, Sep. 2017.

[14] H. Mahmoudi, M. Aleenejad, and R. Ahmadi, "Modulated Model Predictive Control of Modular Multilevel Converters in VSC-HVDC Systems," IEEE Transactions on Power Delivery, vol. 33, no. 5, pp. 2115-2124, Oct. 2018

[15] "Diode-Clamped Multilevel Inverters," in High-Power Converters and AC Drives. John Wiley \& Sons, Ltd, 2016, pp. 143-183. [Online]. Available: https://onlinelibrary.wiley.com/doi/abs/10.1002/9781119156079.ch8

[16] J. Rodriguez and P. Cortes, "Predictive Control of a Three-Phase Neutral-Point Clamped Inverter,' in Predictive Control of Power Converters and Electrical Drives. IEEE, 2012. [Online]. Available: http://ieeexplore.ieee.org/xpl/articleDetails.jsp?arnumber $=6199002$ 